\title{
Influência do déficit hídrico na germinação de sementes e no desenvolvimento inicial de três espécies de Pleurothallidinae (Orchidaceae) ${ }^{1}$
}

\author{
ANGELICA PATRICIA PAVEZZI BARBERO ${ }^{2,4}$, FÁBIO DE BARROS $^{2}$, \\ EMERSON ALVES DA SILVA ${ }^{3}$ e ROGERIO MAMORU SUZUKI ${ }^{2}$
}

(recebido: 25 de novembro de 2010; aceito: 01 de dezembro de 2011)

\begin{abstract}
Influence of water stress on seed germination and early development in three species of Pleurothallidinae (Orchidaceae)). The subtribe Pleurothallidinae has about 4,100 species in 36 genera, and occurs only in the Americas. Acianthera teres (Lindl.) Borba is rupicolous, exposed to light and high temperatures. Octomeria gracilis Lood. ex Lindl. and Octomeria crassifolia Lindl. are epiphytes in forests, but the first grows in moist and the latter in drier areas. The availability of water influences the metabolism at different stages of plant growth. The objective of this study was to evaluate the influence of water deficit induced by the addition of polyethylene glycol 6000 (PEG) to the culture medium, in the germination and initial development of $A$. teres, $O$. crassifolia and $O$. gracilis. Seeds were sown on $\mathrm{MS} / 2$ medium under four treatments: control (without PEG), and with $50 \mathrm{~g} \mathrm{~L}^{-1}, 100 \mathrm{~g} \mathrm{~L}^{-1}$ and $200 \mathrm{~g} \mathrm{~L}^{-1}$ of PEG, inducing water potentials of $-0.53,-0.70,-0.86$ and $-1.60 \mathrm{MPa}$, respectively. Observations were carried out at 45, 120 and 180 days. In $A$. teres the lower the water potential of the medium, the lower the germination rate, and the greater the delay in seedling development. In $O$. crassifolia, the lower the water potential of the medium, the higher the rate of germination, but the development almost equaled between treatments in 180 days. Octomeria gracilis has some tolerance to reduced water potential up to 120 days and grows faster with water potentials of -0.53 and $-0.70 \mathrm{MPa}$.
\end{abstract}

Key words - Epidendroideae, orchids, polyethylene glycol, water potential, water stress

RESUMO - (Influência do déficit hídrico na germinação de sementes e no desenvolvimento inicial de três espécies de Pleurothallidinae (Orchidaceae)). A subtribo Pleurothallidinae possui cerca de 4.100 espécies em 36 gêneros, e ocorre somente nas Américas. Acianthera teres (Lindl.) Borba é rupícola e exposta a luz e a altas temperaturas. Octomeria gracilis Lood. ex Lindl. e Octomeria crassifolia Lindl. são epífitas de florestas, porém, a primeira ocorre em áreas úmidas e a segunda em locais mais secos. A disponibilidade de água influencia o metabolismo nas diversas etapas do desenvolvimento vegetal. Objetivou-se com este trabalho avaliar a influência do déficit hídrico, induzido pela adição de polietileno glicol 6000 (PEG) ao meio de cultura, na germinação e desenvolvimento inicial em A. teres, O. crassifolia e O. gracilis. A semeadura foi efetuada em meio $\mathrm{MS} / 2$, sob quatro tratamentos: controle (sem adição de PEG), e com $50 \mathrm{~g} \mathrm{~L}^{-1}, 100 \mathrm{~g} \mathrm{~L}^{-1}$ e $200 \mathrm{~g} \mathrm{~L}^{-1}$ de PEG, induzindo potenciais hídricos de $-0,53,-0,70,-0,86$ e $-1,60 \mathrm{MPa}$, respectivamente. Foram realizadas análises aos 45 , 120 e 180 dias de cultivo. Em A. teres, observou se que o menor potencial hídrico do meio resulta em menor taxa de germinação e maior retardo do desenvolvimento inicial das plantas. Em O. crassifolia, quanto menor o potencial hídrico do meio, maior a taxa de germinação, contudo, o desenvolvimento foi semelhante entre os tratamentos aos 180 dias. Octomeria gracilis possui certa tolerância a redução do potencial hídrico até 120 dias, e desenvolvimento mais rápido em potenciais hídricos de $-0,53$ e $-0,70 \mathrm{MPa}$.

Palavras-chave - Epidendroideae, estresse hídrico, orquídeas, polietileno glicol, potencial hídrico

\section{Introdução}

$\mathrm{Na}$ natureza, a intensidade e a distribuição das chuvas definem o regime hídrico, influenciando desde o crescimento e a produtividade das plantas até a

1. Parte da tese de doutorado da primeira autora, Programa de Pós Graduação em Biodiversidade Vegetal e Meio Ambiente, Instituto de Botânica, São Paulo, SP, Brasil.

2. Instituto de Botânica, Núcleo de Pesquisa Orquidário do Estado, Avenida Miguel Estéfano 3687, 04301-902 São Paulo, SP, Brasil.

3. Instituto de Botânica, Núcleo de Pesquisa em Fisiologia e Bioquímica, Avenida Miguel Estéfano 3687, 04301-902 São Paulo, SP, Brasil.

4. Autor para correspondência: appbarbero@yahoo.com.br distribuição das populações e a diversidade vegetal nos ecossistemas (Fan \& Neumann 2004). De fato, entre os principais fatores abióticos envolvidos na sobrevivência de espécies epífitas, a umidade é, a curto prazo, o principal fator limitante. Assim, a tolerância ao déficit hídrico nas diversas etapas do desenvolvimento das espécies vegetais, incluindo a germinação, pode ser um fator decisivo no seu estabelecimento e sobrevivência e depende em grande parte de características morfológicas, anatômicas e fisiológicas da semente e da planta.

Mesmo em orquídeas epífitas, que geralmente possuem adaptações a ambientes xerofíticos, períodos de seca provocam alterações fisiológicas, como a redução 
da capacidade fotossintética (Stancato et al. 2001). Da mesma forma que a disponibilidade de água influencia o metabolismo de plantas adultas, também influencia a germinação e o desenvolvimento inicial da plântula, retardando-os ou mesmo inibindo-os, como observado por Zhu et al. (2006) em sementes de Pinus sylvestris L. var. mongolica Litv. e por Takaki (2008), em Oryza sativa $\mathrm{L}$.

A primeira fase da germinação de sementes é a embebição, uma vez que a presença de água dentro da semente reativa o metabolismo e desencadeia uma sequência de processos fisiológicos, estando envolvida direta e indiretamente em todas as demais etapas da germinação (Marcos Filho 2005). A baixa disponibilidade de água para a embebição atrasa ou impede a germinação, havendo um nível mínimo de hidratação que a semente deve atingir para que os processos ocorram, o qual varia de acordo com as características da testa (Verslues et al. 2006).

O método mais adequado para quantificar a água disponível para a semente ou planta é determinar o potencial hídrico ou potencial da água $\left(\Psi_{\mathrm{w}}\right)$ do meio. Através da manipulação do potencial de água do meio pode ser possível verificar as respostas de germinação de espécies a deficiência hídrica.

Vários trabalhos sobre a influência do déficit hídrico induzido pela redução do potencial hídrico do meio na germinação de sementes estão disponíveis na literatura, porém, a maioria deles foi realizada com espécies de angiospermas de interesse agronômico, como estilosante (Delachiave et al. 1986), arroz (Takaki 2008), soja (Braccini et al. 1996), pepino (Torres et al. 1999), milho (Martinelli-Seneme et al. 2000, Tonin et al. 2000), milho-pipoca (Moterle et al. 2006, 2008) e sorgo forrageiro (Oliveira \& Gomes Filho 2009), ou então com nativas lenhosas, como Pinus (Zhu et al. 2006). Também foram encontrados na literatura alguns trabalhos com plantas herbáceas nativas, como algumas espécies de Bromeliaceae (Mantovani \& Iglesias 2008, 2010).

Apesar de Orchidaceae apresentar distribuição cosmopolita, com espécies altamente adaptadas a ambientes xerofíticos, nenhum trabalho sobre a influência do potencial hídrico do meio na germinação de sementes foi encontrado para espécies dessa família, a qual apresenta plantas com diferentes exigências ecológicas. Os poucos trabalhos encontrados na literatura envolvendo orquídeas e déficit hídrico foram realizados com plantas adultas, expostas a períodos de seca, com o objetivo de observar alterações fisiológicas (Zotz \& Tyree 1996, Stancato et al. 2001).
As espécies selecionadas para o presente estudo, Acianthera teres (Lind1.) Borba, Octomeria crassifolia Lindl. e Octomeria gracilis Lodd. ex Lindl., pertencem a subtribo Pleurothallidinae (família Orchidaceae, subfamília Epidendroideae, tribo Epidendreae). São características comuns as três espécies: crescimento simpodial, cauloma não espessado em pseudobulbo, uma folha carnosa ou coriácea por cauloma, flores com sépalas semelhantes entre si, ovário articulado com o pedicelo, cápsula cilíndrica a fusiforme, semente clavada a elipsóide com abertura na extremidade micropilar e embrião elipsóide.

As espécies estudadas, apesar de próximas filogeneticamente e com muitas semelhanças morfológicas entre si, crescem em ambientes distintos e possuem necessidades hídricas diferenciadas, de forma que devem responder de maneiras diferentes a situações de déficit hídrico. Acianthera teres é uma espécie rupícola, de folhas subcilíndricas, inflorescência em racemo e flores alaranjadas até vinosas, ocorrente em campos rupestres da Cadeia do Espinhaço (Minas Gerais e Bahia). Nesse ambiente os principais fatores causadores de estresse são a alta radiação solar, a grande variação térmica diária, os ventos fortes e a pouca quantidade de água e nutrientes disponíveis, o que é acentuado pela escassez de plantas arbóreas nos locais em que ela cresce (Pereira et al. 2009). Octomeria crassifolia é epífita, de folhas planas e coriáceas e flores amarelas, sendo encontrada na Mata Atlântica, no alto dos ramos das árvores, exposta a luz e ao vento, de modo que seu microhabitat é mais seco em relação a outros nas mesmas áreas de floresta. Octomeria gracilis é uma espécie delicada, de folhas semi-cilíndricas e pequenas flores amarelas. É encontrada na Mata Atlântica, como epífita em ramos baixos e protegidos da luz direta na mata densa, portanto em um microhabitat mais úmido e sombreado quando comparado ao das outras duas espécies aqui estudadas. Embora não existam estudos a respeito, acredita-se que as duas espécies de Octomeria apresentem metabolismo do tipo CAM, como ocorre com 57\% das epífitas vasculares (Luttge 2004). O mesmo deve ocorrer com $A$. teres, pois esse tipo de metabolismo é considerado uma resposta ao estresse provocado pela falta de água.

Espera-se que espécies que sofrem diferentes pressões seletivas dos ambientes de ocorrência tenham comportamentos germinativos distintos diante de variações na disponibilidade hídrica. Tendo isto em vista, o objetivo deste trabalho foi observar a influência do déficit hídrico, simulado por adição de polietileno glicol (PEG) no meio de cultura, na germinação e no 
desenvolvimento inicial de plantas de três espécies de Pleurothallidinae, que ocorrem em ambientes com diferentes graus de disponibilidade de água.

\section{Material e métodos}

As sementes para análise foram obtidas, por polinização manual ou natural, de plantas vivas provenientes da coleção do Núcleo de Pesquisa Orquidário do Estado, das quais posteriormente foi herborizada uma amostra para constituir o material testemunho (tabela 1), que foi depositado no Herbário do Estado "Maria Eneyda P. Kauffman Fidalgo" (SP). As sementes foram coletadas de frutos maduros em início de deiscência, cerca de três meses após a polinização das flores, no caso das duas espécies de Octomeria, e por período desconhecido em $A$. teres, uma vez que a planta foi coletada na natureza com frutos em desenvolvimento e observada até o início da deiscência dos frutos. Foram acondicionadas em envelopes de papel manteiga no interior de recipientes plásticos hermeticamente fechados e armazenados a cerca de $4{ }^{\circ} \mathrm{C}$ até a semeadura in vitro.

Tabela 1. Material testemunha depositado.

Table 1. Vouchers deposited.

\begin{tabular}{lc}
\hline Espécie & $\begin{array}{c}\text { Material depositado } \\
\text { em herbário }\end{array}$ \\
\hline $\begin{array}{l}\text { Acianthera teres (Lindl.) } \\
\text { Borba }\end{array}$ & $\begin{array}{c}\text { L.R.S. Guimarães \& T.L. } \\
\text { Laitano 54 (SP) }\end{array}$ \\
Octomeria crassifolia & F. Barros s.n. (SP 401874) \\
Lindl. & F. Barros s.n. (SP 401865) \\
& F. Barros s.n. (SP 401845) \\
Octomeria gracilis Lood. & A.P.P. Barbero 62 (SP) \\
ex Lindl. & A.P.P. Barbero 61 (SP) \\
& A.P.P. Barbero 60 (SP) \\
& A.P.P. Barbero 59 (SP) \\
\hline
\end{tabular}

Antes do início do experimento, a viabilidade das sementes foi verificada através do método de coloração com tetrazólio (Lakon 1949), que consiste em imergir amostras de sementes, previamente embebidas em água durante 30 minutos, em uma solução aquosa $(0,5 \%)$ de cloreto de 2, 3, 5 trifenil tetrazólio. Foram consideradas sementes viáveis aquelas com embrião vermelho e inviáveis aquelas com embriões brancos ou sem embriões. Foi calculada a porcentagem de sementes viáveis de cada espécie estudada, levando-se em conta a relação de sementes viáveis e o total de sementes analisadas. As amostras de sementes usadas nesse teste foram descartadas.

Previamente a semeadura, as sementes foram embebidas em água destilada esterilizada, tratadas com uma solução de $15 \%(\mathrm{v} / \mathrm{v})$ de hipoclorito de sódio comercial (Candida $\left.{ }^{\circledR}\right)$
(2,0-2,5\% de cloro ativo) durante 10 minutos, sob agitação constante, para desinfestação, e lavadas três vezes em água destilada esterilizada. A vidraria utilizada foi esterilizada em autoclave a $120^{\circ} \mathrm{C}$ e $1,3 \mathrm{~atm}$ durante 30 minutos.

Para a avaliação da germinabilidade, as sementes foram submetidas a quatro diferentes potenciais hídricos, que foram obtidos pela adição de polietileno glicol (PEG 6000) durante o preparo do meio de cultura, conforme estabelecido por Michel \& Kaufmann (1973), nas concentrações de $0 \mathrm{~g} \mathrm{~L}^{-1}$ (controle, tratamento 1), $50 \mathrm{~g} \mathrm{~L}^{-1}$ (tratamento 2), $100 \mathrm{~g} \mathrm{~L}^{-1}$ (tratamento 3) e $200 \mathrm{~g} \mathrm{~L}^{-1}$ (tratamento 4) de meio de cultura, que induziram potenciais hídricos médios de $-0,53,-0,70$, $-0,86$ e $-1,60 \mathrm{MPa}$, respectivamente. Os potenciais hídricos dos meios de cultura foram medidos utilizando-se um psicrômetro de ponto de orvalho (modelo WP4 Dew Point Meter, Decagon Devices, Pullman, EUA).

As sementes foram cultivadas in vitro, em meio MS (Murashige \& Skoog 1962), com metade da concentração de macro e micronutrientes (meio $\mathrm{MS} / 2$ ), com o $\mathrm{pH}$ ajustado para 5,8 $\pm 0,05$. Os meios de cultura foram esterilizados em autoclave a $120^{\circ} \mathrm{C}$ e 1,3 atm durante 15 minutos (Suzuki et al. 2010).

O delineamento experimental utilizado foi o inteiramente casualizado, constando de quatro tratamentos (meios de cultura), representados por repetições (três frascos de cultivo) para cada tratamento, os quais foram mantidos em sala de cultura com temperatura média de $25 \pm 2{ }^{\circ} \mathrm{C}$, sob fotoperíodo de 12 horas e intensidade luminosa de aproximadamente $20 \mu \mathrm{mol} \mathrm{m} \mathrm{s}^{-2}$, obtida com lâmpadas fluorescentes.

O desenvolvimento das plântulas foi acompanhado periodicamente, desde o início da germinação, passando pela formação de protocormos, diferenciação de tecidos, surgimento da primeira estrutura semelhante a folha, até a emissão de folhas e raízes, sendo realizadas análises aos 45, 120 e 180 dias após a inoculação das sementes. Em cada uma das análises, os frascos de cultura foram abertos em câmara de fluxo laminar, e foram retiradas duas amostras de cada frasco. Cada amostra foi colocada sobre lâmina de vidro quadriculada, em uma área de $2 \mathrm{~cm}^{2}$, e analisada em estereomicroscópio, segundo Suzuki et al. (2009).

Foi observada, na primeira análise, a germinabilidade (porcentagem de embriões vivos), considerando-se como germinadas as sementes com embriões clorofilados, e nas análises aos 120 e 180 dias foram observadas as porcentagens de sementes/protocormos em cada uma das cinco fases de desenvolvimento inicial consideradas nesse trabalho, modificadas de Milaneze (1997) e Stewart \& Kane (2006): fase $0=$ semente cujo embrião não se desenvolveu; fase $1=$ protocormo desenvolvido, mas morto; fase 2 = protocormo vivo; fase 3 = plântula com uma estrutura semelhante à folha; fase 4 = plântula com duas ou mais folhas; e fase $5=$ plântula com folhas e raízes (figuras 1-6).

Para as porcentagens de germinação e fases de desenvolvimento inicial foi realizado tratamento estatístico a partir da análise de variância fatorial $3 \times 4$ (espécies $\times$ potenciais hídricos utilizados) (TWO-WAY ANOVA) 


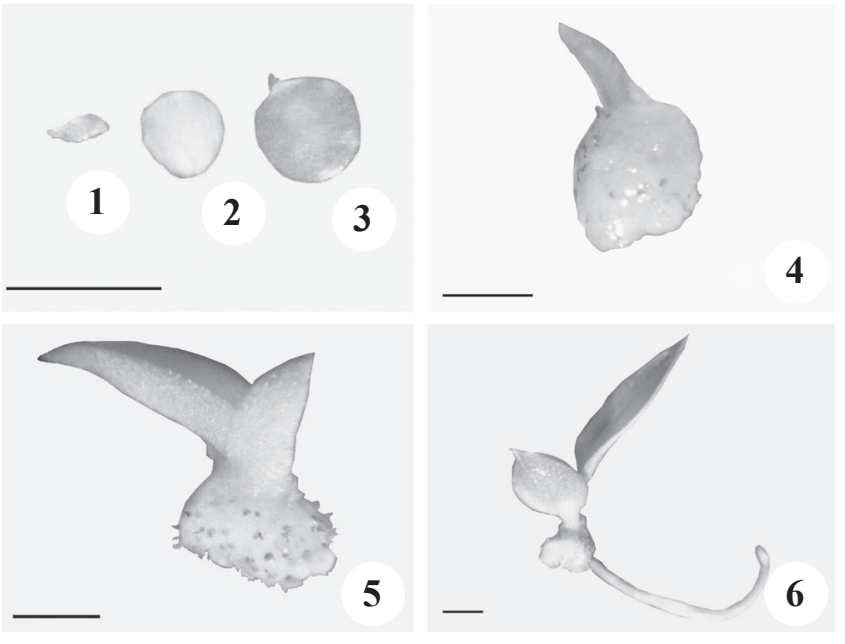

Figuras 1-6. Fases de desenvolvimento observadas em Acianthera teres, Octomeria crassifolia e Octomeria gracilis. 1. Fase 0 (semente não germinada). 2. Fase 1 (protocormo morto). 3. Fase 2 (protocormo vivo, sem estruturas diferenciadas). 4. Fase 3 (plântula com a primeira estrutura semelhante a folha). 5. Fase 4 (plântula com duas ou mais folhas). 6. Fase 5 (plântula com folhas e raiz). Barra $=0,5 \mathrm{~mm}$ (1-3); $1 \mathrm{~mm}(4-6)$.

Figures 1-6. Stages of development observed in Acianthera teres, Octomeria crassifolia, and Octomeria gracilis. 1. Stage 0 (seed not germinated). 2. Stage 1 (protocorms dead). 3. Stage 2 (protocorms live without differentiated structures). 4. Stage 3 (seedling with the first sheet-like structure). 5. Stage 4 (seedling with two or more sheets). 6. Stage 5 (seedling with leaf and root). $B a r=0.5 \mathrm{~mm}(1-3) ; 1 \mathrm{~mm} \mathrm{(4-6).}$ seguido do teste de separação das médias utilizando-se o teste de Tukey em nível de 5\% de significância. Os dados em porcentagem foram transformados em arco seno $(x+10)^{1 / 2}$ (Ranal et al. 2009).

\section{Resultados e Discussão}

Nas três espécies estudadas, a análise de germinabilidade realizada aos 45 dias de cultivo revelou embriões vivos, clorofilados, porém sem diferenciação de estruturas semelhantes a folhas e tampouco presença de raízes (tabela 2). Foram observadas somente estruturas intumescidas, arredondadas ou cônicas. As sementes que não germinaram apresentaram embriões não clorofilados, de coloração branca. Foi verificada, ainda, a ocorrência de sementes que germinaram, iniciaram o desenvolvimento em protocormos e morreram em seguida, apresentando coloração branca e tons de castanho (figura 2).

Aos 120 dias de cultivo, nas três espécies, foram encontrados protocormos com uma ou mais estruturas semelhantes a folhas, presença de tricomas na porção basal de vários indivíduos, porém sem emissão de raízes (tabela 2, figura 5). Tais tricomas absorvem água e nutrientes, além de serem importantes para a fixação do protocormo no substrato (Kraus et al. 2006).

Aos 180 dias de cultivo, alguns indivíduos de $A$. teres apresentaram raízes no tratamento 1 , e em $O$. gracilis foram observadas raízes em indivíduos nos tratamentos 1 e 2 , o que não ocorreu nos tratamentos 3 e 4. Octomeria crassifolia desenvolveu-se mais

Tabela 2. Germinação e desenvolvimento inicial de Acianthera teres, Octomeria crassifolia e Octomeria gracilis em quatro potenciais hídricos. Os valores referem-se a média das porcentagens. Valores seguidos de letras diferentes apresentaram variação significativa entre os tratamentos, segundo teste de Tukey $(P<0,05)$. Valores seguidos de "ns" não apresentaram variação significativa entre os tratamentos.

Table 2. Germination and initial development of Acianthera teres, Octomeria crassifolia and Octomeria gracilis under four water potentials. The values are the average percentages. Values followed by different letters showed significant variation between treatments according to Tukey test $(P<0.05)$. Values followed by "ns" did not show significant variation between treatments.

\begin{tabular}{|c|c|c|c|c|c|c|c|c|c|}
\hline \multirow{2}{*}{ Tratamentos } & & \multirow{2}{*}{$\begin{array}{c}45 \text { dias } \\
\text { Embriões vivos }\end{array}$} & \multicolumn{3}{|c|}{120 dias } & \multicolumn{4}{|c|}{180 dias } \\
\hline & & & Fase 2 & Fase 3 & Fase 4 & Fase 2 & Fase 3 & Fase 4 & Fase 5 \\
\hline \multirow[t]{3}{*}{ Espécies } & A. teres & $19,700 \mathrm{~b}$ & $17,425 \mathrm{a}$ & $7,000 \mathrm{~b}$ & $8,425 \mathrm{ab}$ & $8,113 \mathrm{a}$ & $7,363 \mathrm{a}$ & $25,575 \mathrm{a}$ & $1,04 \mathrm{~ns}$ \\
\hline & O. crassifolia & $27,013 \mathrm{a}$ & $10,600 \mathrm{a}$ & $9,838 \mathrm{ab}$ & $2,488 \mathrm{~b}$ & $5,875 \mathrm{a}$ & $4,000 \mathrm{a}$ & $5,750 \mathrm{~b}$ & $0 \mathrm{~ns}$ \\
\hline & O. gracilis & $10,738 \mathrm{c}$ & $13,825 \mathrm{a}$ & $15,400 \mathrm{a}$ & $17,100 \mathrm{a}$ & $10,388 \mathrm{a}$ & 8,138 a & $27,900 \mathrm{a}$ & $2,08 \mathrm{~ns}$ \\
\hline Potenciais & $-0,53$ & $29,200 \mathrm{a}$ & $10,717 \mathrm{~b}$ & $7,650 \mathrm{~b}$ & $20,333 \mathrm{a}$ & $1,650 \mathrm{~b}$ & $2,567 \mathrm{~b}$ & $31,067 \mathrm{a}$ & $2,57 \mathrm{~ns}$ \\
\hline \multirow[t]{3}{*}{ hídricos (MPa) } & $-0,70$ & $21,067 \mathrm{~b}$ & $7,817 \mathrm{~b}$ & $11,783 \mathrm{~b}$ & $11,267 \mathrm{ab}$ & $2,950 \mathrm{~b}$ & $12,683 \mathrm{a}$ & $30,750 \mathrm{a}$ & $1,58 \mathrm{~ns}$ \\
\hline & $-0,86$ & $23,317 \mathrm{ab}$ & $24,500 \mathrm{a}$ & $23,550 \mathrm{a}$ & $5,750 \mathrm{~b}$ & $14,417 \mathrm{a}$ & $10,750 \mathrm{a}$ & $17,150 \mathrm{~b}$ & $0 \mathrm{~ns}$ \\
\hline & $-1,60$ & $3,017 \mathrm{c}$ & $12,767 \mathrm{ab}$ & $0,001 \mathrm{c}$ & $0,001 \mathrm{c}$ & $13,483 \mathrm{a}$ & $0,001 \mathrm{~b}$ & $0,001 \mathrm{c}$ & $0 \mathrm{~ns}$ \\
\hline
\end{tabular}


lentamente, não apresentando raízes em nenhum dos tratamentos até os seis meses de cultivo (tabela 2).

As três espécies apresentaram comportamentos germinativos distintos entre si, mostrando-se adaptadas aos ambientes em que ocorrem. A morfologia das sementes não influenciou o comportamento germinativo, já que as sementes das três espécies são semelhantes entre si (A.P.P. Barbero \& F. Barros, dados não publicados).

O tratamento 4 inibiu a germinação nas três espécies estudadas, possivelmente porque o potencial hídrico do meio é muito negativo $(-1,60 \mathrm{MPa})$, impedindo a ativação do metabolismo do embrião. Mesmo as poucas sementes que embeberam e iniciaram seu desenvolvimento, não conseguiram concluir o processo germinativo: houve alta taxa de mortalidade e os indivíduos que sobreviveram mantiveram-se na fase 2 de desenvolvimento, sem a diferenciação de estruturas. Delachiave et al. (1986) e Torres et al. (1999) observaram que a redução do potencial hídrico do meio reduz a embebição. O aumento da concentração de solutos provoca diminuição do gradiente hídrico no sistema substrato/semente, bloqueando o movimento da água e, consequentemente, reduzindo a velocidade de germinação (Torres et al. 1999). Segundo Dell'Aquila \& Spada (1992), se o potencial hídrico do substrato de germinação de sementes de trigo for inferior a $-1,5 \mathrm{MPa}$, a síntese protéica no embrião é reduzida, pois esse é um processo sensível a disponibilidade hídrica e, consequentemente, não há o desenvolvimento dos tecidos.

Em $A$. teres, observou-se que a redução no potencial hídrico do meio diminuiu a porcentagem de germinação (figura 7). Esse resultado é semelhante ao encontrado na literatura para Aechmea nudicaulis (L.) Griseb., Neoregelia cruenta (Graham) L.B. Sm. e Vriesea neoglutinosa Mez, que são bromélias terrestres de restinga (Mantovani \& Iglesias 2008, 2010), e também para Oryza sativa L. (Takaki 2008) e Clusia hilariana Schltdl. (Cavalcante et al. 2010). No sorgo forrageiro a germinação ocorre, porém é retardada pela diminuição do potencial hídrico do meio (Oliveira \& Gomes Filho 2009). Em espécies que não possuem adaptação ao déficit hídrico, esse tipo de comportamento é esperado, uma vez que baixos potenciais hídricos indicam pouca água disponível para a realização de trabalho na planta, impedindo que a sequência de eventos da germinação ocorra ou tornando o metabolismo mais lento que em condições ótimas.

A. teres é a única das três espécies estudadas que responde substancialmente a pequenas reduções de potencial hídrico, como do tratamento $1(-0,52 \mathrm{MPa})$ para o tratamento $2(-0,70 \mathrm{MPa})$, em que a porcentagem de germinação cai pela metade. Isso sugere que a germinação nessa espécie depende de disponibilidade

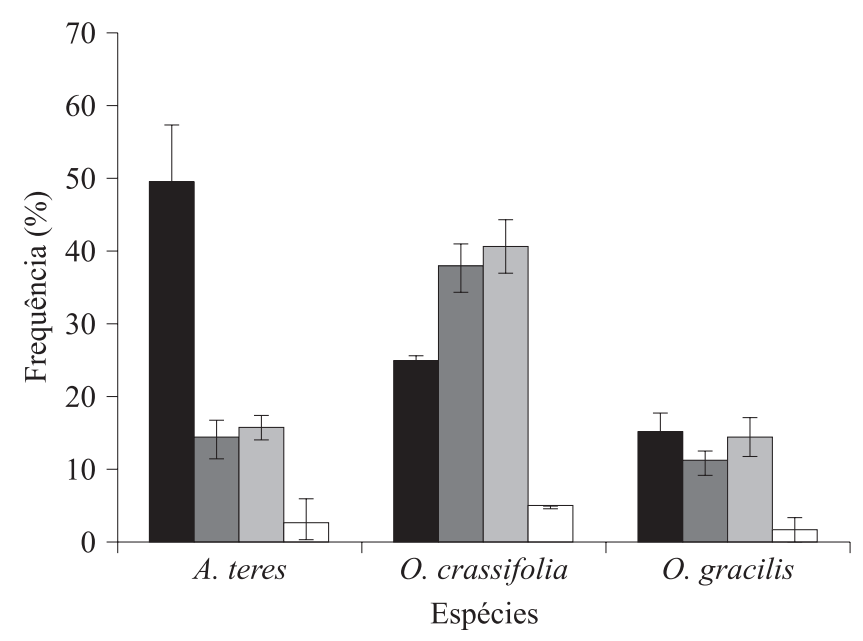

Figura 7. Germinação de Acianthera teres, Octomeria crassifolia e Octomeria gracilis em meios de cultura com potenciais hídricos diferentes, aos 45 dias de cultivo, representando a porcentagem de indivíduos vivos em cada tratamento. Barras verticais representam o desvio padrão $(\mathbf{\square}=$ $-0,53 \mathrm{MPa} ; \square=-0,70 \mathrm{MPa} ; \square=-0,86 \mathrm{MPa} ; \square=1,60 \mathrm{MPa})$.

Figure 7. Germination of Acianthera teres, Octomeria crassifolia, and Octomeria gracilis in culture media with different water potentials, at 45 days of culture, representing the percentage of living individuals in each treatment. Vertical bars represent the standard deviation $(\mathbf{\square}=-0,53 \mathrm{MPa}$; $\square=-0,70 \mathrm{MPa} ; \square=-0,86 \mathrm{MPa} ; \square=1,60 \mathrm{MPa})$.

hídrica constante, enquanto as duas espécies de Octomeria podem germinar dentro de uma faixa de disponibilidade hídrica. Esses dados demonstram a importância de estratégias fenológicas para garantir o sucesso reprodutivo da espécie, como a dispersão das sementes em épocas do ano com maior disponibilidade hídrica. Alcantarea imperialis (Carrière) Harms e Pitcairnia flammea Lindl., por exemplo, duas bromélias rupícolas como $A$. teres, são menos sensíveis a potenciais hídricos reduzidos, o que favorece seu estabelecimento em campos rupestres (Pereira et al. 2009). Além disso, outros fatores ambientais podem interagir com a disponibilidade hídrica para garantir esse sucesso reprodutivo, como observado por Socolowski \& Takaki (2004) na germinação de Jacaranda mimosifolia D. Don, espécie considerada pioneira em matas secundárias: a diminuição do potencial hídrico afeta negativamente a germinação, porém, em condições de déficit hídrico moderado e temperatura elevada, a luz apresenta um efeito promotor da germinação maior que em outras condições, garantindo o sucesso germinativo necessário a uma espécie pioneira. Já em Dyckia tuberosa (Vell.) Beer, uma bromélia que ocorre no cerrado, a luz não é um fator limitante da germinação, mas a temperatura a 
afeta de forma significativa, sendo a temperatura ótima relativamente alta (entre 30 e $35^{\circ} \mathrm{C}$ ), indicando que essas sementes são capazes de germinar em áreas abertas e expostas a radiação (Vieira et al. 2007).

Aos 120 dias de cultivo de $A$. teres, observou-se que a porcentagem de sementes que não germinaram aumentou com a diminuição do potencial hídrico do meio e que, à medida que o potencial diminuiu, o desenvolvimento dos protocormos vivos foi mais lento, o que é evidenciado pela porcentagem de indivíduos nas fases 2, 3 e 4 (figura 8A). O retardo no desenvolvimento, na medida em que se reduz o potencial hídrico do meio, também é evidente na análise realizada aos 180 dias de cultivo (figura 9A). Observou-se desenvolvimento mais homogêneo no tratamento 1 , com todas as plântulas vivas já portando duas ou mais folhas, e algumas apresentando raízes. No tratamento 2 houve indivíduos vivos com uma ou mais estruturas semelhantes a folhas, no entanto, sem presença de raízes, e no tratamento 3, a heterogeneidade e o retardo no desenvolvimento foram ainda maiores, com indivíduos vivos sem estruturas diferenciadas, e outros com uma, duas ou mais estruturas semelhantes a folha. No tratamento 4, a germinabilidade atingiu apenas $20 \%$ e os protocormos sobreviventes não desenvolveram estruturas diferenciadas, sejam folhas ou raízes. Esses resultados indicam que $A$. teres, apesar de ser rupícola, não é adaptada ao déficit hídrico, ao menos na fase de germinação.

Octomeria crassifolia e O. gracilis, embora sejam epífitas e semelhantes morfologicamente, apresentaram comportamentos diferentes entre si em relação a variação de potencial hídrico do meio de cultura. Aos 45 dias de cultivo percebe se que a porcentagem de germinação aumentou em $O$. crassifolia à medida que o potencial hídrico do meio diminuiu até $-0,86 \mathrm{MPa}$, que foi o potencial hídrico que induziu a maior porcentagem de germinação de sementes (figura 7). Portanto, essa espécie apresenta melhor resposta germinativa em situação de disponibilidade intermediária de água. Já a porcentagem de germinação de 0 . gracilis (figura 7) foi semelhante nos três primeiros tratamentos, indicando que a espécie apresenta relativa tolerância a diminuição do potencial hídrico do meio até $-0,86 \mathrm{MPa}$, já que não responde significativamente a essas mudanças. No entanto, nessa espécie a porcentagem de germinação foi menor que em O. crassifolia. Tolerância semelhante foi observada por Moterle et al. $(2006,2008)$ no cultivar BRS Angela e em dois híbridos de milho pipoca (SC $002 \times$ BRS Angela e Zélia $\times$ BRS Angela), e atribuíram tal tolerância ao fato de que o cultivar BRS Angela apresenta grande número de genótipos e, consequentemente, grande plasticidade genética frente a variações ambientais.
Outras espécies epífitas de mata apresentaram comportamento germinativo diferente do observado nas duas espécies de Octomeria aqui estudadas. As bromélias Vriesea heterostachys (Baker) L.B. Sm. e Vriesea
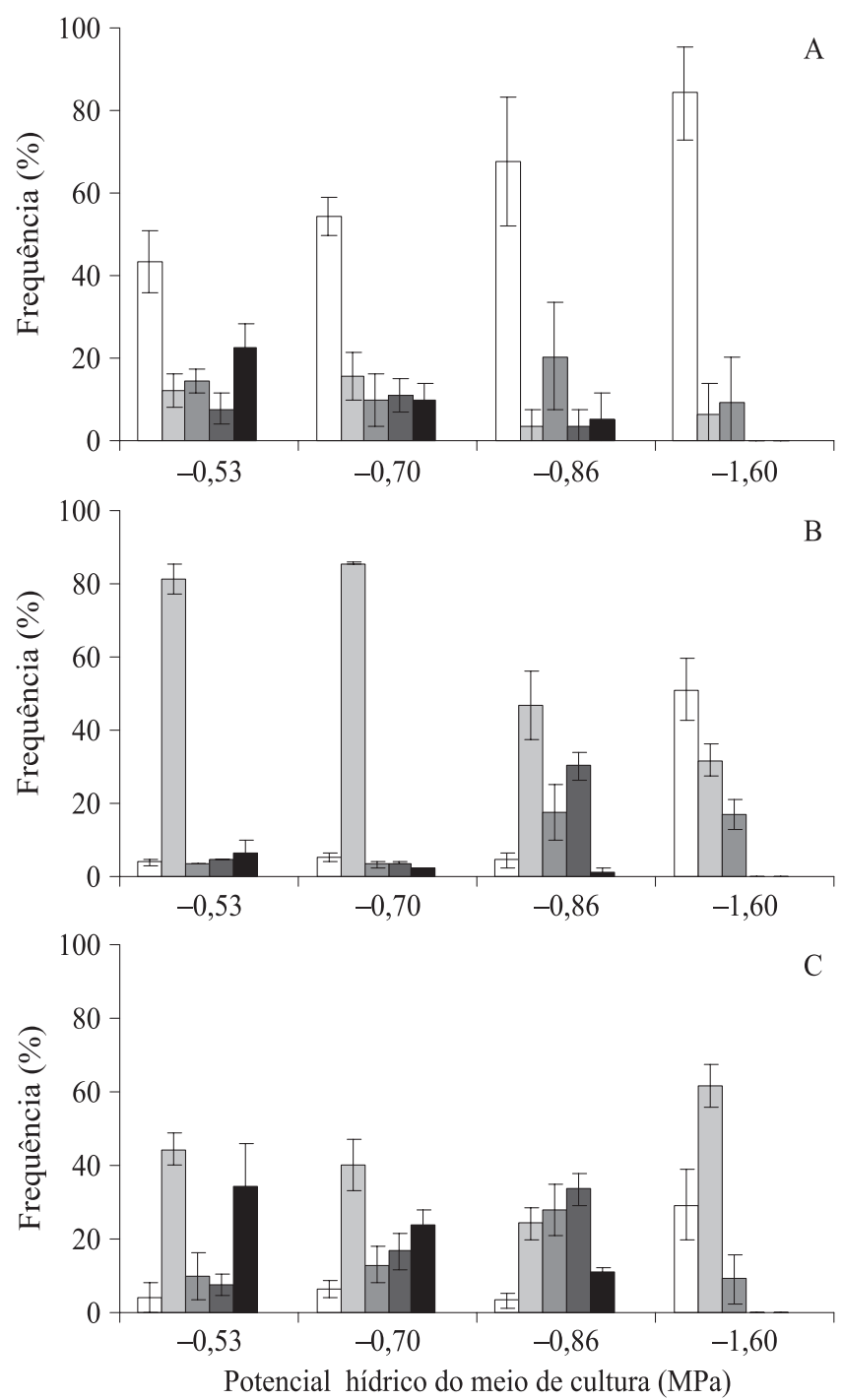

Figura 8. Desenvolvimento inicial das três espécies estudadas, aos 120 dias de cultivo, indicando a porcentagem de indivíduos em cada uma das fases de desenvolvimento para os quatro tratamentos. A. Acianthera teres. B. Octomeria crassifolia. C. Octomeria gracilis. Barras verticais representam o desvio padrão $(\square=$ fase $0 ; \square=$ fase $1 ; \square=$ fase $2 ; \square=$ fase $3 ; \boldsymbol{\square}=$ fase 4 ; $\mathbb{Q}=$ fase 5). Fases descritas nas figuras 1-6.

Figure 8. Early development of three species studied, at 120 days of cultivation, indicating the percentage of individuals in each stage of development for each treatment. A. Acianthera teres. B. Octomeria crassifolia. C. Octomeria gracilis. Vertical bars represent the standard deviation $(\square=$ stage 0 ;

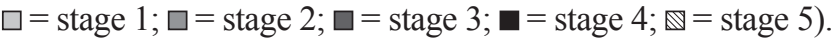
Stages described in figures 1-6. 
penduliflora L.B. Sm. têm a germinação prejudicada pela redução do potencial hídrico do meio, mesmo germinando em ampla faixa de temperatura e sendo insensíveis às condições de luz (Pereira et al. 2009) Isso mostra que espécies distintas ocupando um mesmo habitat podem apresentar estratégias fenológicas distintas.
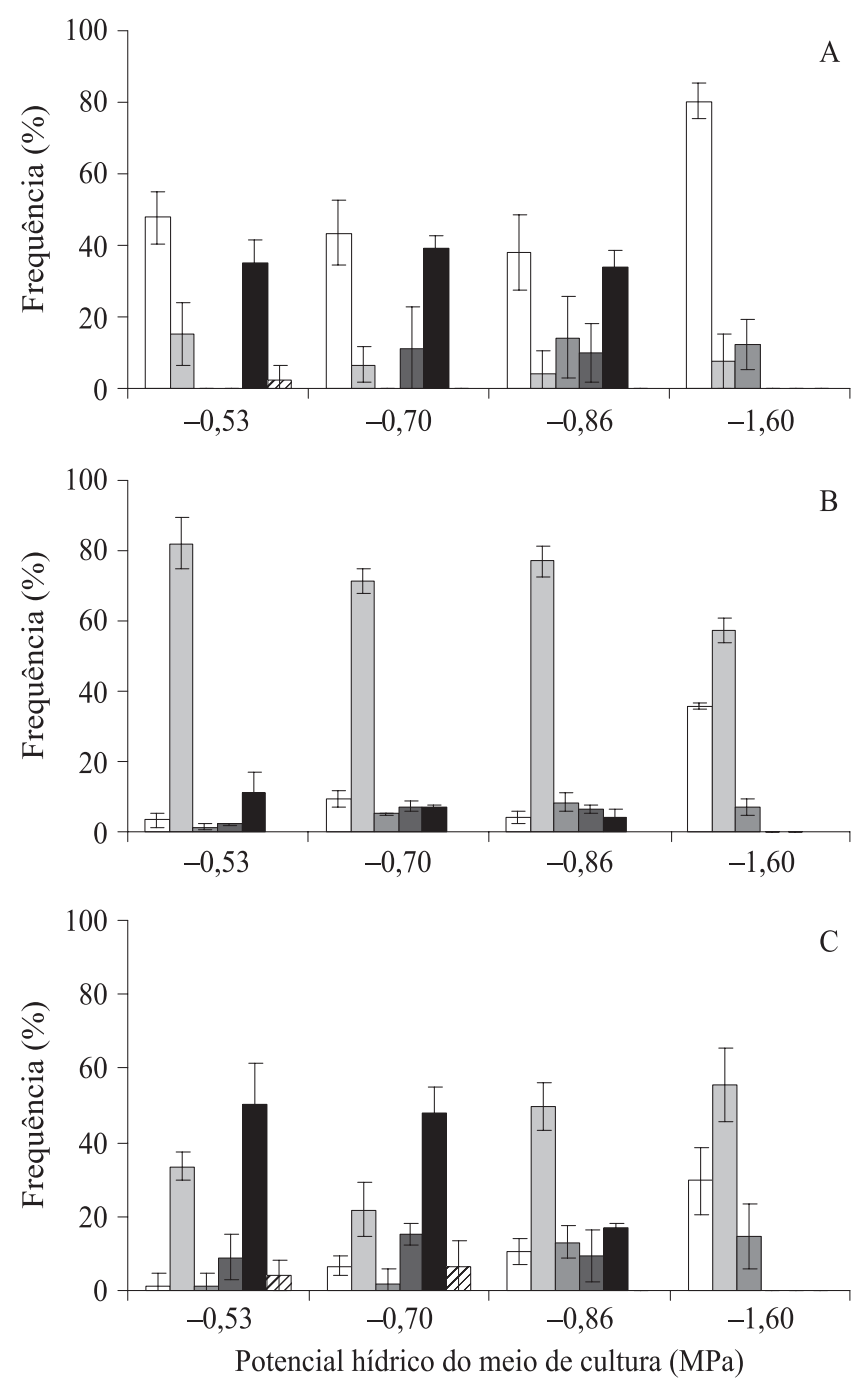

Figura 9. Desenvolvimento inicial das três espécies estudadas, aos 180 dias de cultivo, indicando a porcentagem de indivíduos em cada uma das fases de desenvolvimento para os quatro tratamentos. A. Acianthera teres. B. Octomeria crassifolia. C. Octomeria gracilis. Barras verticais representam o desvio padrão ( $\square=$ fase $0 ; \square=$ fase $1 ; \square=$ fase $2 ; \square=$ fase $3 ; \boldsymbol{\square}=$ fase 4 ; $\mathbb{\mathbb { N }}=$ fase 5). Fases descritas nas figuras 1-6.

Figure 9. Early development of three species studied, at 180 days of cultivation, indicating the percentage of individuals in each stage of development for each treatment. A. Acianthera teres. B. Octomeria crassifolia. C. Octomeria gracilis. Vertical bars represent the standard deviation $(\square=$ stage 0 ; $\square=$ stage $1 ; \square=$ stage $2 ; \square=$ stage $3 ; \square=$ stage $4 ; \mathbb{\mathbb { }}=$ stage 5 ). Stages described in figures 1-6.
Aos 120 dias de cultivo, O. crassifolia mostrou altas taxas de mortalidade nos tratamentos 1 e 2, sendo o tratamento $3(-0,86 \mathrm{MPa})$ o mais adequado para o desenvolvimento dos protocormos, com a maior porcentagem de indivíduos vivos, e também com uma ou mais estruturas semelhantes a folha (figura 8B). Porém, aos 180 dias observou-se maior taxa de mortalidade nesse tratamento, atingindo os mesmos níveis de $-0,53$ e $-0,70 \mathrm{MPa}$ (figura 9B), o que indica que o potencial hídrico de - $0,86 \mathrm{MPa}$ é adequado para a germinação e o desenvolvimento inicial até o quarto mês, mas dificulta o estabelecimento da plântula. Não foram encontrados na literatura trabalhos envolvendo a influência do potencial hídrico do meio de cultura na germinação de sementes com resultados semelhantes aos observados para $O$. crassifolia.

Em O. gracilis, aos 120 dias de cultivo, observou-se que no tratamento 3 houve menor mortalidade de protocormos, porém com um retardo no desenvolvimento em relação aos tratamentos 1 e 2 (figura $8 \mathrm{C}$ ). O tratamento 1 apresentou desenvolvimento mais rápido e homogêneo, com a maior porcentagem de protocormos portando duas ou mais folhas, dentre todos os tratamentos. Já aos 180 dias de cultivo, a taxa de mortalidade aumentou muito no tratamento 3 , e os tratamentos 1 e 2 apresentaram os melhores resultados, com altas taxas de indivíduos portando duas ou mais folhas, e com alguns indivíduos apresentando raízes (figura 9C). Os resultados indicam que o potencial hídrico -0,86 MPa é o mais adequado para o desenvolvimento até o quarto mês de cultivo, porém provoca maior taxa de mortalidade a partir deste período, prejudicando o estabelecimento da plântula. Percebe-se, portanto, que para a germinação de sementes de $O$. gracilis, a disponibilidade de água não interfere significativamente, mas é fator determinante para o estabelecimento da fase 4 de desenvolvimento.

Considerando-se a germinação, $A$. teres, que ocorre em ambiente mais seco em relação as outras duas espécies, não se mostrou adaptada ao déficit hídrico como $O$. crassifolia, que teve maior porcentagem de germinação em potenciais hídricos mais baixos. No entanto, com relação ao desenvolvimento inicial, A teres mostrou-se mais adaptada, apresentando folhas eraízes em um intervalo de tempomenor. Comparando $A$. teres, espécie proveniente de ambiente mais seco, com $O$. gracilis, espécie proveniente de ambiente mais úmido, percebe-se que na germinação esta última se mostrou mais tolerante ao déficit hídrico, mas o desenvolvimento inicial mostrou-se mais lento em relação ao de A. teres.

Com base no exposto, percebe-se que os comportamentos germinativos das duas espécies de 
Octomeria são diferentes quanto à tolerância ao déficit hídrico, tanto na germinação quanto na velocidade de desenvolvimento das plântulas, sendo os resultados compatíveis com os ambientes em que elas ocorrem. Octomeria crassifolia ocorre em microhabitat mais aberto e seco, e apresenta maior porcentagem de germinação em potenciais mais baixos; já $O$. gracilis ocorre em ambiente mais fechado e úmido, mas sujeito a períodos de seca, como ocorre com as epífitas de um modo geral, de forma que certa tolerância ao estresse hídrico é fundamental para sua sobrevivência. Octomeria gracilis desenvolveu-se mais rapidamente, apresentando, mais cedo, maior porcentagem de plântulas na fase 4 e presença de indivíduos na fase 5. O desenvolvimento mais rápido desta espécie, em relação a $O$. crassifolia, de modo a aproveitar o período de maior disponibilidade hídrica, pode ser importante para uma espécie com menor tolerância ao estresse hídrico durante a germinação.

Já $A$. teres, apesar de ser rupícola, não é mais adaptada ao déficit hídrico do que as outras espécies, especialmente na germinação. Isso pode ser explicado pelo fato de que, em campos rupestres, onde a espécie ocorre, as principais causas de estresse são o excesso de radiação solar e as altas temperaturas que as rochas alcançam ao longo do dia. Uma hipótese é que o déficit hídrico, nas condições dos campos rupestres, pode ser amenizado pela neblina cuja ocorrência na área, principalmente à noite, é um fenômeno bem conhecido. Isso compensaria a alta taxa de evaporação nos horários com maior incidência de radiação solar. Outra explicação possível é que a deiscência dos frutos e a dispersão das sementes ocorram na estação chuvosa, o que permitiria a planta evitar situações de estresse hídrico durante o período de germinação. Porém não existem dados que possam corroborar essas hipóteses aqui levantadas e, portanto, não é possível esclarecer essa questão com os dados disponíveis no momento.

Agradecimentos - O autor F. Barros agradece ao CNPq, pela bolsa de produtividade em pesquisa recebida (processo 306889/2010-2).

\section{Referências bibliográficas}

BRACCINI, A.L., RUIZ, H.A., BRACCINI, M.C.L. \& REIS, M.S. 1996. Germinação e vigor de sementes de soja sob estresse hídrico induzido por soluções de cloreto de sódio, manitol e polietileno glicol. Revista Brasileira de Sementes 18:10-16.
CAVALCANTE, A., BRAZ, M.I.G. \& MATTOS, E.A. 2010. Germination biology and seedling growth of Clusia hilariana Schltdl., a dominant CAM tree of drought prone sandy coastal plains. Ecological Research 25: 781-787.

DELACHIAVE, M.E.A., RODRIGUES, J.D., MORAES, J.A.P.V., PEDRAS, J.F., RODRIGUES, S.D. \& BOARO, C.S.F. 1986. Germinação de sementes de Stylosanthes guianensis. IV - Potencial água e embebição. Revista Brasileira de Sementes 8:55-61.

DELL'AQUILA, A. \& SPADA, P. 1992. Regulation of protein synthesis in germinating wheat embryos under polyethylene glycol and salt stress. Seed Science Research 2:75-80.

FAN, L. \& NEUMANN, P.M. 2004. The spatially variable inhibition by water deficit of maize root growth correlates with altered profiles of proton flux and cell wall pH. Plant Physiology 135:2291-2300.

KOZLOWSKI, T.T. \& PALLARDY, S.G. 1996. Physiology of wood plants. Academic Press, San Diego.

KRAMER, P.J. \& BOYER, J.S. 1995. Water relations of plants and soils. Academic Press, San Diego.

KRAUS, J.E., KERBAUY, G.B. \& MONTEIRO, W.R. 2006. Desenvolvimento de protocormos de Catasetum pileatum Rchb.f. in vitro: aspectos estruturais e conceituais. Hoehnea 33:177-184.

LAKON, G. 1949. The topographical tetrazolium method for determining the germinating capacity of seeds. Plant Physiology 24:389-394.

LUTTGE, U. 2004. Ecophysiology of crassulacean acid metabolism (CAM). Annals of Botany 93:629-652.

MANTOVANI, A. \& IGLESIAS, R.R. 2008. Factors limiting seed germination of terrestrial bromeliads in the sandy coastal plains (restinga) of Maricá, Rio de Janeiro, Brazil. Rodriguésia 59: 135-150.

MANTOVANI, A. \& IGLESIAS, R.R. 2010. The effect of water stress on seed germination of three terrestrial bromeliads from restinga. Revista Brasileira de Botânica 33:201-205.

MARCOS FILHO, J. 2005. Fisiologia de sementes de plantas cultivadas. Fundação de Estudos Agrários Luiz de Queiroz - FEALQ, Piracicaba.

MARTINELLI-SENEME, A., MARTINS, C.C. \& NAKAGAWA, J. 2000. Germinação de milho cv. AL-34 em função do tamanho da semente e do potencial hídrico do substrato. Revista Brasileira de Sementes 22:126-130.

MICHEL, B.E. \& KAUFMANN, M.R. 1973. The osmotic potential of polyethylene glycol 6000. Plant Physiology 51:914-916.

MILANEZE, A.M. 1997. Estudos em orquídeas nativas do Brasil: morfologia de sementes e cultivo assimbiótico. Tese de doutorado, Universidade Estadual Paulista, Rio Claro. 
MOTERLE, L.M, LOPES, P.C., BRACCINI,A.L. \& SCAPIM, C.A. 2006. Germinação de sementes e crescimento de plântulas de cultivares de milho pipoca submetidas ao estresse hídrico e salino. Revista Brasileira de Sementes 28:169-176.

MOTERLE, L.M., SCAPIM, C.A., BRACCINI, A.L., RODOVALHO, M.A. \& BARRETO, R.R. 2008. Influência do estresse hídrico sobre o desempenho fisiológico de sementes de híbridos simples de milho pipoca. Ciência e Agrotecnologia 32:1810-1817.

MURASHIGE, T. \& SKOOG, F. 1962. A revised medium for rapid growth and bioassays with tobacco tissue cultures. Physiologia Plantarum 15:473-497.

OLIVEIRA, A.B. \& GOMES FILHO, E. 2009. Germinação e vigor de sementes de sorgo forrageiro sob estresse hídrico e salino. Revista Brasileira de Sementes 31:48-56.

PEREIRA, A.R., ANDRADE, A.C.S., PEREIRA, T.S., FORZZA, R.C. \& RODRIGUES, A.S. 2009. Comportamento germinativo de espécies epífitas e rupícolas de Bromeliaceae do Parque Estadual de Ibitipoca, Minas Gerais, Brasil. Revista Brasileira de Botânica 32:827-838.

RANAL, M.A., SANTANA, D.G., FERREIRA, W.R. \& MENDES-RODRIGUES, C. 2009. Calculating germination measurements and organizing streadsheets. Revista Brasileira de Botânica 32:849-855.

SOCOLOWSKI, F. \& TAKAKI, M. 2004. Germination of Jacaranda mimosifolia (D. Don - Bignoniaceae) seeds: effects of light, temperature and water stress. Brazilian Archives of Biology and Technology 47:785-792.

STANCATO, G.C., MAZZAFERA, P. \& BUCKERIDGE, M.S. 2001. Effect of a drought period on the mobilization of non structural carbohydrates, photosynthetic efficiency and water status in an epiphytic orchid. Plant Physiology and Biochemistry 39:1009-1016.

STEWART, S.L. \& KANE, M.E. 2006. Asymbiotic seed germination and in vitro seedling development of Habenaria macroceratitis (Orchidaceae) a rare Florida terrestrial orchid. Plant Cell, Tissue and Organ Culture $86: 147-158$.
SUZUKI, R.M., MOREIRA, V.C., NAKABASHI, M. \& FERREIRA, W.M. 2009. Estudo da germinação e crescimento in vitro de Hadrolaelia tenebrosa (Rolfe) Chiron \& V.P. Castro (Orchidaceae), uma espécie da flora brasileira ameaçada de extinção. Hoehnea 36: 657-666.

SUZUKI, R.M., ALMEIDA, V., PESCADOR, R. \& FERREIRA, W.M. 2010. Germinação e crescimento in vitro de Cattleya bicolor Lindley (Orchidaceae). Hoehnea 37:731-742.

TAKAKI, M. 2008. Effect of water stress on seed germination and seedling growth in Oryza sativa L. Biologia Plantarum 32:238-240.

TONIN, G.A., CARVALHO, N.M., KRONKA, S.N. \& FERRAUDO, A.S. 2000. Influência do cultivar e do vigor no desempenho germinativo de sementes de milho em condições de estresse hídrico. Revista Brasileira de Sementes 22:276-279.

TORRES, S.B., VIEIRA, E.L. \& MARCOS FILHO, J. 1999. Efeitos do estresse hídrico na germinação e no desenvolvimento de plântulas de pepino. Revista Brasileira de Sementes 21:59-63.

VERSLUES, P.E., AGARWAL, M., KATIYAR-AGARWAL, S., ZHU, J. \& ZHU, J.K. 2006. Methods and concepts in quantifying resistance to drought, salt and freezing, abiotic stress that affect plant water status. The Plant Journal 45:523-539.

VIEIRA, D.C.M., SOCOLOWSKI, F. \& TAKAKI, M. 2007. Germinação de sementes de Dyckia tuberosa (Vell.) Beer (Bromeliaceae) sob diferentes temperaturas em luz e escuro. Revista Brasileira de Botânica 30: 183-188.

ZHU, J., KANG, H., TAN, H. \& XU, M. 2006. Effects of drought stresses induced by polyethilene glycol on germination of Pinus sylvestris var. mongolica seeds from natural and plantation forests on sandy land. Journal of Forest Research 11:319-328.

ZOTZ, G. \& TYREE, M.T. 1996. Water stress in the epiphytic orchid, Dimerandra emarginata (G. Meyer) Hoehne. Oecologia 107:151-159. 